Dieses Dokument ist eine Zweitveröffentlichung (Postprint) /

This is a self-archiving document (accepted version):

Rui Ma, Simon Buhr, Zoltan Tibenszky, Martin Kreißig, Frank Ellinger

\title{
An Analogue Baseband Chain for a Magnetic Tunnel Junction Based RF
} Signal Detector

Erstveröffentlichung in / First published in:

2019 IEEE Nordic Circuits and Systems Conference (NORCAS): NORCHIP and International Symposium of System-on-Chip (SoC), Helsinki, 2019. IEEE Explore. ISBN 978-1-7281-2769-9

DOI: https://doi.org/10.1109/NORCHIP.2019.8906918

Diese Version ist verfügbar / This version is available on:

https://nbn-resolving.org/urn:nbn:de:bsz:14-qucosa2-365209 


\title{
An Analogue Baseband Chain for a Magnetic Tunnel Junction Based RF Signal Detector
}

\author{
Rui Ma, Simon Buhr, Zoltán Tibenszky, Martin Kreißig, Frank Ellinger \\ Chair for Circuit Design and Network Theory \\ Technische Universität Dresden, 01062 Dresden, Germany
}

\begin{abstract}
This work presents an analogue baseband (BB) chain for a magnetic tunneling junction (MTJ) based radiofrequency (RF) signal detector fully integrated in a hybrid CMOS-MTJ technology. The BB chain contains a $6^{\text {th }}$-order $g_{m}-C$ low-pass filter (LPF), a BB amplifier, a comparator, and a current bank. According to measurement results, the $6^{\text {th }}$-order LPF with a cut-off frequency of $10 \mathrm{MHz}$ consumes a very low DC power of $2.41 \mathrm{~mW}$. Its DC power consumption per pole of $0.4 \mathrm{~mW}$ is the lowest among the state-of-the-art LPFs. The LPF can be also switched on and off very fast within $110 \mathrm{~ns}$. With the fast switchability and the low power consumption, the LPF outperforms the state of the art. Furthermore, the complete BB chain can transform a $2.5 \mathrm{mV}_{\mathrm{PP}}, 5 \mathrm{Mbps} \mathrm{BB}$ signal into digital data with a bit error rate fewer than $10^{-6}$. The $\mathrm{BB}$ chain consumes $2.85 \mathrm{~mW}$ including all bias circuits. To achieve power efficiency, the BB chain is designed to operate under an aggressive duty-cycling mode. The switch-on time of the BB chain is within $200 \mathrm{~ns}$.

Index Terms-Spintronic, magnetic tunnel junction, low-pass filters, CMOS integrated analogue circuits, frequency detector
\end{abstract}

\section{INTRODUCTION}

\section{A. Magnetic Tunnel Junction}

Magnetic tunnel junctions (MTJ) are nanometre-scale devices that typically consist of multiple ferromagnetic layers separated by a nonmagnetic layer. There are two characteristics recently discovered in the MTJs making them very attractive in RF-related applications. The first one is the DC-to-RF convertibility with which an MTJ can operate naturally as a current controlled oscillator (CCO) [1]. The second one is the RF-to-DC property, hence an inverse phenomenon to the first one, known as the spin-torque diode effect [2]. In this case, when the DC current is suppressed and an RF signal is injected with a frequency that conforms to the intrinsic oscillation frequency of the MTJ, the MTJ outputs a DC signal. Recent studies have shown that the RF signal detection sensitivity (DS) of MTJ-based diodes can be higher $\left(\mathrm{DS} \approx 10^{4} \mathrm{mV} / \mathrm{mW}\right.$, [3]) and much higher (DS $\approx 10^{5} \mathrm{mV} / \mathrm{mW}$, [4]) than CMOS diodes $\left(\mathrm{DS} \approx 4 \cdot 10^{3} \mathrm{mV} / \mathrm{mW}\right.$ ), thereby paving a lightning path for MTJ-based RF detection in telecommunication markets.

\section{B. MTJ Based RF Signal Detector}

It has been demonstrated that MTJs standalone can function as both the $\mathrm{CCO}$ and $\mathrm{RF}$ detector [5] [6] [7] [8] [9]. A milestone step that needs to be taken is integration of the MTJs into conventional CMOS technologies, which has been carried out within the frame of GREAT project [10]. One of the project goals is to demonstrate a fully integrated MTJ based RF signal detector where the RF-to-DC functionality of the MTJs can be

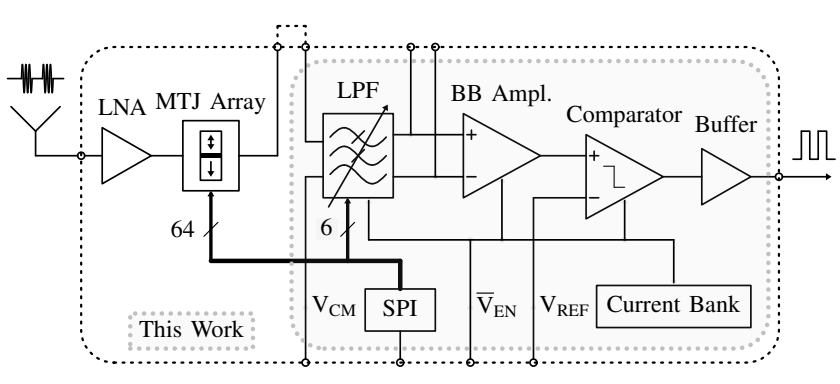

Fig. 1. Principle diagram of the MTJ based RF signal detector

fully exploited. Fig. 1 shows the block diagram of the newly developed MTJ based RF signal detector.

Here an MTJ array similar to the one introduced in [10] is implemented as the core of the RF detection. Since each MTJ is designed to respond to a single and narrow RF band, the major advantage of the MTJ based receiver compared to a conventional direct conversion receiver lies in the fact there is no need of an RF band-pass filter, thus largely reducing the design complexity, silicon area and cost. Our newly developed MTJ based RF signal detector is targeted to operate in a truly multiple-band standard from 1 to $10 \mathrm{GHz}$.

The prototype circuit is fabricated in a Towerjazz (TJ) hybrid CMOS-MTJ technology. The active device layer and the first two metal layers, metal layer 1 and 2, are implemented in a TJ $180 \mathrm{~nm}$ CMOS technology. The MTJ layers are located above metal layer 2. Above the MTJ layers, metal 3 and 4 layers are fabricated in a TJ $130 \mathrm{~nm}$ CMOS technology.

\section{Analogue BB Chain}

The first step that has been accomplished and is to be presented in this work is the design and implementation of an analogue BB chain for the MTJ-based frequency detector. As shown in Fig. 1, the BB chain, which consists of a LPF, a BB amplifier, a comparator and a current bank, transforms the BB signal generated by the MTJ into a digital bit stream with a maximal data rate below $10 \mathrm{Mbps}$. Since the output voltage of an MTJ lies in the range of several millivolts to several ten millivolts [4], the BB chain is specified to have a sensitivity of $-50 \mathrm{dBm}\left(2 \mathrm{mV}_{\mathrm{PP}}\right)$ at a $50 \Omega$ system. In addition, to achieve power efficiency, the BB chain is designed to work in an aggressive duty-cycling mode with a duty cycle fewer than $0.1 \%$. A fast settling time $\mathrm{T}_{\mathrm{s}}$ of the $\mathrm{BB}$ chain is specified to lie within $200 \mathrm{~ns}$. 


\section{Circuit Design}

\section{A. Design of a $6^{\text {th }}$-Order $L P F$}

To eliminate both the input RF signal, noise and simultaneously enhance the weak BB signal generated by the MTJ, the LPF is targeted to have a cut-off frequency $\mathrm{f}_{\mathrm{c}}$ of $10 \mathrm{MHz}$ and a transition steepness of $-120 \mathrm{~dB} /$ decade. To avoid the shift of $f_{c}$ and pass-band voltage gain $A_{L P}$ due to process variations in fabrication, $\mathrm{f}_{\mathrm{c}}$ should be adjustable from $5 \mathrm{MHz}$ to $30 \mathrm{MHz}$, as well as $A_{L P}$ from 0 to $20 \mathrm{~dB}$. Moreover, the LPF should settle very fast, which is specified within $200 \mathrm{~ns}$. At last, the LPF should also have a low power consumption $\mathrm{P}_{\mathrm{DC}}$ of $<4 \mathrm{~mW}$.

To realize the filter characteristic of $-120 \mathrm{~dB} /$ decade, we designed a $6^{\text {th }}$-order LPF that consists of three cascaded $2^{\text {nd }}$ order LPFs with the same topology. The transfer function of the $6^{\text {th }}$-order LPF is thus related to the transfer function of the $2^{\text {nd }}$-order LPF:

$$
\mathrm{G}_{\mathrm{LP}, 6 \text { th }}(\mathrm{s})=\left(\mathrm{G}_{\mathrm{LP}, 2 \text { nd }}(\mathrm{s})\right)^{3}
$$

1) Tow-Thomas Topology Based OTA-C $2^{\text {nd }}$-Order LPF: Our design focus is now shifted to realization of the $2^{\text {nd }}$-order LPF with a fast $T_{S}$ and low $P_{D C}$. As is shown in Fig. 2, here we choose a $\mathrm{g}_{\mathrm{m}}-\mathrm{C}$ topology named after Tow-Thomas (TT) for our $2^{\text {nd }}$-order LPF [11] [12]. According to the studies in [12], the TT topology compared to other topologies such as multiple feeback loop provides following benefits: lower transconductance $\left(\mathrm{g}_{\mathrm{m}}\right)$ required for its OTAs, lower DC power consumption, faster settling and less mismatch due to no resistors required in the signal path. From Fig. 2, we can derive the filter's transfer function $\mathrm{G}_{\mathrm{LP}, 2 \text {, nd }}(\mathrm{s})=\frac{\mathrm{V}_{\text {out }}}{\mathrm{V}_{\text {in }}}$ :

$$
\mathrm{G}_{\mathrm{LP}, 2 \mathrm{nd}, 2 \mathrm{nd}}(\mathrm{s})=\frac{\mathrm{A}_{\mathrm{LP}, 2 \mathrm{nd}} \omega_{0}^{2}}{\mathrm{~s}^{2}+\frac{\omega_{0}}{\mathrm{Q}} \mathrm{s}+\omega_{0}^{2}}=\frac{\frac{\mathrm{g}_{\mathrm{T} 2} \mathrm{~g}_{\mathrm{T} 4}}{\mathrm{C}_{1} \mathrm{C}_{2}}}{\mathrm{~s}^{2}+\frac{\mathrm{g}_{\mathrm{T}}}{\mathrm{C}_{2}} \mathrm{~s}+\frac{\mathrm{g}_{\mathrm{T} 1} \mathrm{~g}_{\mathrm{T} 2}}{\mathrm{C}_{1} \mathrm{C}_{2}}}
$$

where its cutoff frequency $f_{c, 2 n d}$, voltage gain $A_{L P, 2 n d}$, and quality factor $\mathrm{Q}$ can be described as the following formula:

$$
\mathrm{f}_{\mathrm{c}, 2 \text { nd }}=\frac{1}{2 \pi} \sqrt{\frac{\mathrm{g}_{\mathrm{T} 1} \mathrm{~g}_{\mathrm{T} 2}}{\mathrm{C}_{1} \mathrm{C}_{2}}} ; \mathrm{A}_{\mathrm{LP}, 2 \text { nd }}=\frac{\mathrm{g}_{\mathrm{T} 4}}{\mathrm{~g}_{\mathrm{T} 1}} ; \mathrm{Q}=\frac{\sqrt{\mathrm{g}_{\mathrm{T} 1} \mathrm{~g}_{\mathrm{T} 2}}}{\mathrm{~g}_{\mathrm{T} 3}} \sqrt{\frac{\mathrm{C}_{2}}{\mathrm{C}_{1}}}
$$

For the sake of design simplicity, we choose $\mathrm{g}_{\mathrm{T} 1}=\mathrm{g}_{\mathrm{T} 2}=\mathrm{g}_{\mathrm{T} 3}$ $=\mathrm{g}_{\mathrm{T} 0}$. Thus, Eq. (3) can be simplified into:

$$
\mathrm{f}_{\mathrm{c}, 2 \mathrm{nd}}=\frac{1}{2 \pi} \frac{\mathrm{g}_{\mathrm{T} 0}}{\mathrm{C}_{0}} ; \mathrm{A}_{\mathrm{LP}, 2 \mathrm{nd}}=\frac{\mathrm{g}_{\mathrm{T} 4}}{\mathrm{~g}_{\mathrm{T} 0}} ; Q=\sqrt{\frac{\mathrm{C}_{2}}{\mathrm{C}_{1}}}
$$

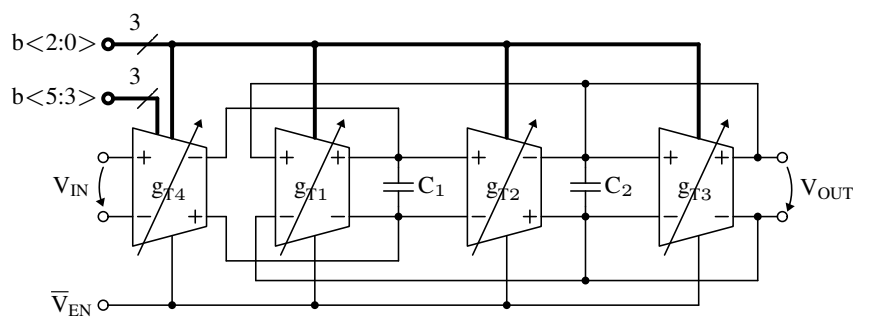

Fig. 2. Schematic of the TT-based $2^{\text {nd }}$-order LPF
Via Eq. (4) we can first see that the filter's quality factor is independent of its $\mathrm{f}_{\mathrm{c}, 2 \text { nd }}$ and $\mathrm{A}_{\mathrm{LP}, 2 \text { nd }}$. Moreover, we design here $Q=\sqrt{2} / 2$ due to the compromise between a relatively fast settling time and a small overshoot effect for an under-damped $2^{\text {nd }}$-order filter. This leads to $\mathrm{C}_{1}=2 \mathrm{C}_{2}=2 \mathrm{C}_{0}$. Furthermore, we can tune $f_{c, 2 n d}$ by only changing $g_{T 0}$. To make the gain $\mathrm{A}_{\mathrm{LP}, 2 \text { nd }}$ tunable, $\mathrm{g}_{\mathrm{T} 4}$ is designed to have a different digital tuning unit from $\mathrm{g}_{\mathrm{T} 0}$.

2) OTA Design: As is shown in Fig. 3, the proposed OTA consists of an input $\mathrm{g}_{\mathrm{m}}$ stage, an output impedance enhancement stage, a digital tuning stage, a common mode feedback (CMFB) loop and several power-disable switches. The input and output stages together build up a well-known current mirror cascode topology which provides the benefit to tune $g_{m}$ with ease. $g_{m}$ can be defined by the DC output current of the output stage which is adjustable via the digital tuning unit. The output current of the positive side of the output stage $\mathrm{I}_{\mathrm{O},+}$ consists of the current flowing through $\mathrm{M}_{3 \mathrm{a}}$ and the current flowing through all the PMOS branches of the digital unit, which can be described as:

$$
\mathrm{I}_{\mathrm{O},+}=\mathrm{I}_{\mathrm{D}, 3 \mathrm{a}}+\sum_{\mathrm{i}=0}^{n-1} \mathrm{~b}_{\mathrm{i}} 2^{i-1} \mathrm{I}_{\mathrm{D}, 3 \mathrm{a}}=\mathrm{I}_{\mathrm{IN}}+\sum_{\mathrm{i}=0}^{n-1} \mathrm{~b}_{\mathrm{i}} 2^{i-1} \mathrm{I}_{\mathrm{IN}}
$$

where $b_{i}$ refers to the $i^{\text {th }}$ digital bit value, either 1 or 0 , that determines the on-off state of the PMOS switches $\mathrm{M}_{13,14}$. In addition, $n$ is the total number of the digital branches that are connected in parallel. For the OTAs $\mathrm{g}_{\mathrm{T} 1}, \mathrm{~g}_{\mathrm{T} 2}$ and $\mathrm{g}_{\mathrm{T} 3}$, their $n$ is 3. For the OTA $\mathrm{g}_{\mathrm{T} 4}$, its $n$ is 6 .

The CMFB loop is needed to stabilize the common mode (CM) output voltage. The reference $\mathrm{CM}$ voltage $\mathrm{V}_{\mathrm{CM}}$ is set to be $V_{\mathrm{DD}} / 2$. Capacitors $\mathrm{C}_{1 \mathrm{a}}$ and $\mathrm{C}_{1 \mathrm{~b}}$ with a value of $100 \mathrm{fF}$ are used to perform frequency compensation, thus eliminating the risk of instability due to the CMFB loop. According to simulation results, at all the digital bit configurations, the OTA has an open loop gain $>30 \mathrm{~dB}$, and its phase margin is $>60^{\circ}$. Table I shows the OTA's main components values.

TABLE I

MAIN COMPONENT VALUES OF THE OTA

\begin{tabular}{l|llllllll}
\hline W/L & $\mathrm{M}_{1 \mathrm{a}, 1 \mathrm{~b}}$ & $\mathrm{M}_{2 \mathrm{a}, 2 \mathrm{~b}, 3 \mathrm{a}, 3 \mathrm{~b}}$ & $\mathrm{M}_{4 \mathrm{a}, 4 \mathrm{~b}}$ & $\mathrm{M}_{5 \mathrm{a}, 5 \mathrm{~b}}$ & $\mathrm{M}_{6 \mathrm{a}, 6 \mathrm{~b}}$ & $\mathrm{M}_{10 \mathrm{a}}$ & $\mathrm{M}_{10 \mathrm{~b}}$ & $\mathrm{M}_{15 \mathrm{a}, 15 \mathrm{~b}}$ \\
\hline
\end{tabular}
\begin{tabular}{l|llllllll}
\hline$\mu \mathrm{m} / \mu \mathrm{m}$ & $60 / 0.36$ & $12 / 0.36$ & $100 / 0.18$ & $60 / 0.18$ & $9 / 0.36$ & $5 / 0.36$ & $10 / 0.36$ & $6 / 0.36$ \\
\hline
\end{tabular}

3) Simulation of the $6^{\text {th }}$-Order LPF: To make the cutoff frequency of the $6^{\text {th }}$-order LPF $\mathrm{f}_{\mathrm{c}, 6 \text { th }}$ adjustable from 5 to $30 \mathrm{MHz}$ and its pass-band gain $A_{\mathrm{LP}, 6 \text { th }}$ tunable from 0 to $30 \mathrm{~dB}$, the input current for each OTA $\mathrm{I}_{\mathrm{IN}}$ is set to $10 \mu \mathrm{A}$ and $\mathrm{C}_{0}$ to $250 \mathrm{fF}$. The simulated settling time of the filter is of around $105 \mathrm{~ns}$. Table II summarizes the simulated results of the OTA and the $6^{\text {th }}$-order LPF's $\mathrm{f}_{\mathrm{c}, \text { th }}$ when the bit configuration is $\mathrm{b}<2: 0>$ from 000 to 111 , and $\mathrm{b}<5: 3>$ equals 000 .

\section{B. BB Amplifier and Comparator}

Fig. 4 shows the schematic of the proposed BB amplifier and comparator. According to simulation results, the $\mathrm{BB}$ amplifier has a $40-\mathrm{dB}$ voltage gain with a $-3 \mathrm{~dB}$ bandwidth of $40 \mathrm{MHz}$. The comparator compares the analogue BB signal with a DC 


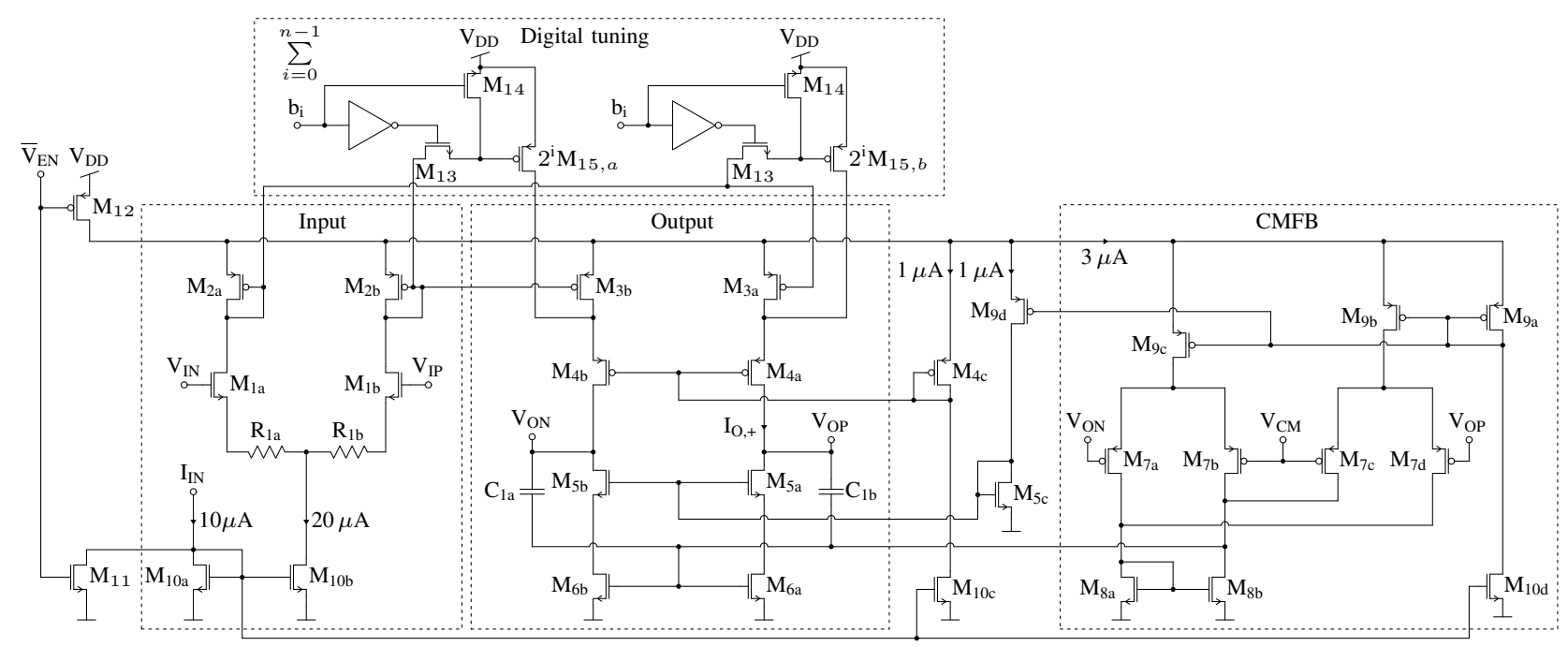

Fig. 3. Simplified schematic of the proposed OTA

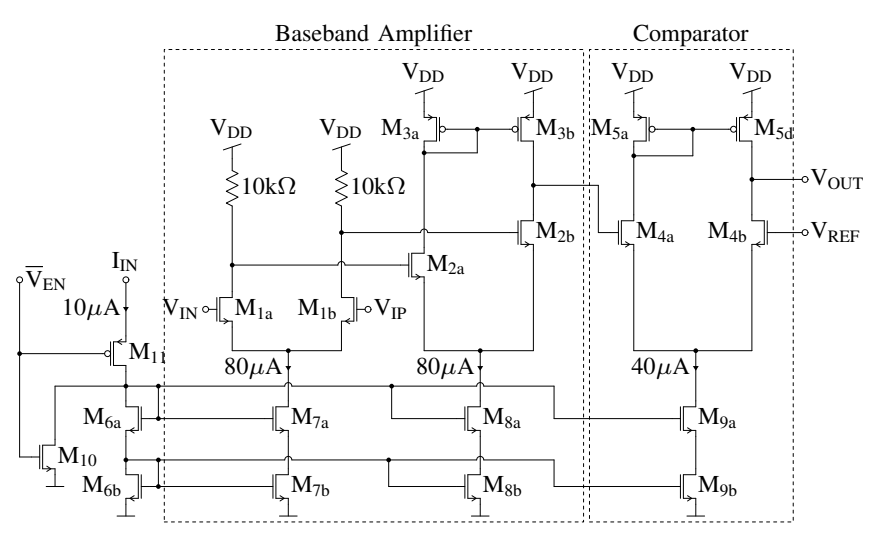

Fig. 4. Schematic of the proposed BB amplifier and comparator

reference voltage set via its input pin $\mathrm{V}_{\mathrm{REF}}$. The $\mathrm{BB}$ amplifier and the comparator can be switched on and off together via the low enable signal $\overline{\mathrm{V}}_{\mathrm{EN}}$. The simulated turn-on time of the two blocks together is $50 \mathrm{~ns}$. When $\overline{\mathrm{V}}_{\mathrm{EN}}=0$, the two parts draw in total $210 \mu \mathrm{A}$ from a $1.8 \mathrm{~V}$ supply. Table III shows the main components values of this circuit.

TABLE II

SIMULATED RESULTS OF THE $6^{\text {TH }}$-ORDER LPF

\begin{tabular}{c|cccccccc}
\hline $\mathrm{b}<2: 0>$ & 000 & 001 & 010 & 011 & 100 & 101 & 110 & 111 \\
\hline $\mathrm{I}_{0,+} / \mu \mathrm{A}$ & 10 & 15 & 20 & 25 & 31 & 37 & 42 & 47 \\
\hline $\mathrm{g}_{\mathrm{m}} / \mu \mathrm{S}$ & 165 & 250 & 325 & 410 & 500 & 590 & 670 & 755 \\
\hline $\mathrm{I}_{\mathrm{DD}, 6 \mathrm{th}} / \mathrm{mA}$ & 0.665 & 0.81 & 0.935 & 1.06 & 1.21 & 1.345 & 1.46 & 1.591 \\
\hline $\mathrm{f}_{\mathrm{c}, 6 \mathrm{th}} / \mathrm{MHz}$ & 3.8 & 7 & 10 & 13.5 & 17.8 & 22.5 & 26 & 30.9 \\
\hline
\end{tabular}

TABLE III

MAIN COMPONENT VALUES OF THE BB AMPLIFIER AND COMPARATOR

\begin{tabular}{c|ccccccc}
\hline $\mathrm{W} / \mathrm{L}$ & $\mathrm{M}_{1 \mathrm{a}, \mathrm{b}}$ & $\mathrm{M}_{2 \mathrm{a}, 2 \mathrm{~b}}$ & $\mathrm{M}_{3 \mathrm{a}, 3 \mathrm{~b}}$ & $\mathrm{M}_{4 \mathrm{a}, 4 \mathrm{~b}}$ & $\mathrm{M}_{5 \mathrm{a}, 5 \mathrm{~b}}$ & $\mathrm{M}_{6 \mathrm{a}, 6 \mathrm{~b}}$ & $\mathrm{M}_{7 \mathrm{a}, 7 \mathrm{~b}, 8 \mathrm{a}, 8 \mathrm{~b}}$ \\
\hline$\mu \mathrm{m} / \mu \mathrm{m}$ & $20 / 0.36$ & $20 / 0.18$ & $4 / 0.54$ & $60 / 0.36$ & $20 / 0.18$ & $4.5 / 0.36$ & $36 / 0.36$
\end{tabular}

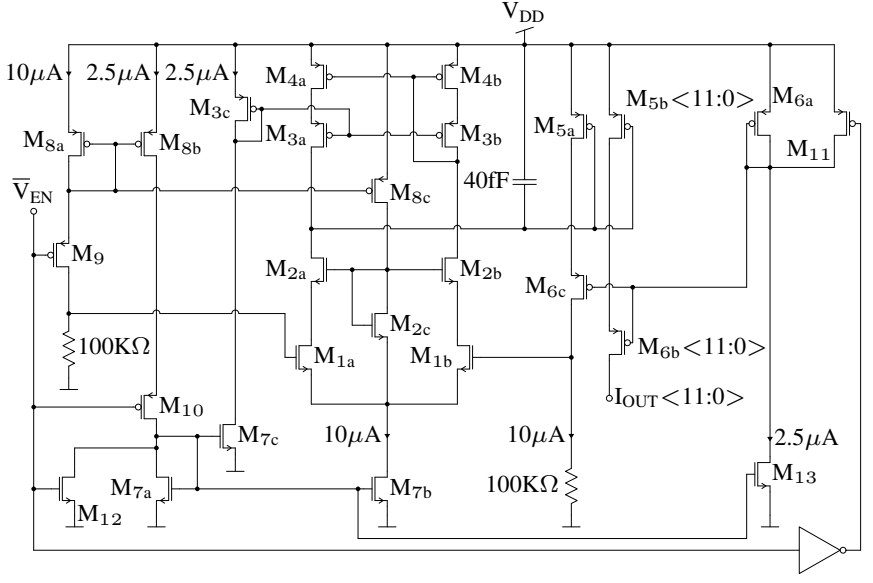

Fig. 5. Schematic of the proposed current bank

\section{Current Bank}

Fig. 4 shows the schematic of the proposed current bank. This current bank provides 12 outputs $\mathrm{I}_{\mathrm{OUT}}<11: 0>$ for the LPF, BB amplifer and comparator. Each output $\mathrm{I}_{\mathrm{OUT}}<\mathrm{x}>$ sources $10 \mu \mathrm{A}$. The current bank can be switched on and off via $\overline{\mathrm{V}}_{\mathrm{EN}}$. The simulated settling time of the output current $\mathrm{I}_{\text {OUT }}<\mathrm{x}>$ is $78 \mathrm{~ns}$. When $\overline{\mathrm{V}}_{\mathrm{EN}}=0$, the current bank excluding the currents on the output paths consumes $37.5 \mu \mathrm{A}$ from a $1.8 \mathrm{~V}$ supply. Table IV shows the main components values of the designed current bank.

TABLE IV

MAIN COMPONENT VALUES OF THE CURRENT BANK

\begin{tabular}{c|ccccccccc}
\hline $\mathrm{W} / \mathrm{L}$ & $\mathrm{M}_{1 \mathrm{a}, 1 \mathrm{~b}}$ & $\mathrm{M}_{2 \mathrm{a}, 2 \mathrm{~b}}$ & $\mathrm{M}_{3 \mathrm{a}, 3 \mathrm{~b}}$ & $\mathrm{M}_{4 \mathrm{a}, 4 \mathrm{~b}}$ & $\mathrm{M}_{5 \mathrm{a}, 5 \mathrm{~b}}$ & $\mathrm{M}_{6 \mathrm{a}}$ & $\mathrm{M}_{6 \mathrm{~b}, 6 \mathrm{c}}$ & $\mathrm{M}_{7 \mathrm{a}}$ & $\mathrm{M}_{7 \mathrm{~b}}$ \\
\hline$\mu \mathrm{m} / \mu \mathrm{m}$ & $4 / 0.18$ & $2 / 20$ & $4 / 0.18$ & $2 / 0.72$ & $4 / 1$ & $1 / 3.6$ & $41 / 0.18$ & $4 / 0.18$ & $16 / 0.18$ \\
\hline
\end{tabular}




\section{Digital Control}

To enable the external digital control of the circuit, a customized slave SPI is implemented on the chip. To communicate with this slave SPI, an STM based micro-controller PCB is developed. Moreover, a Python based graphical user interface is developed to perform experiments efficiently.

\section{EXPERIMENTAL RESUlts}

A die photograph of the completely integrated frequency detector is shown in Fig. 6. The BB chain excluding the digital SPI occupies a silicon area of $0.3 \mathrm{~mm}^{2}$. For test purposes, the chip is wire-bonded on a PCB. Fig. 6 and Fig. 7 show the photograph and the schematic of this PCB, respectively. On the PCB, the positive input of the LPF, which is connected to a $50 \Omega$ resistor, is used as the RF signal input of the circuit. The negative input of the LPF is biased to the common mode voltage of the circuit $\mathrm{V}_{\mathrm{DD}} / 2$. In addition, a broadband fully differential buffer (Linear LTC6417) with a $-3 \mathrm{~dB}$ small signal bandwidth of $1.6 \mathrm{GHz}$ is used as the differential $50 \Omega$ output buffer for the LPF. A broadband balun is used to convert the filter's differential output to a single-ended output.

\section{A. Charaterization of the $6^{\text {th }}$-Order LPF}

A vector analyzer Rohde\&Schwarz ZVL-6 was used to obtain the S-parameter of the circuit. Fig. 8 shows the 8 fre-

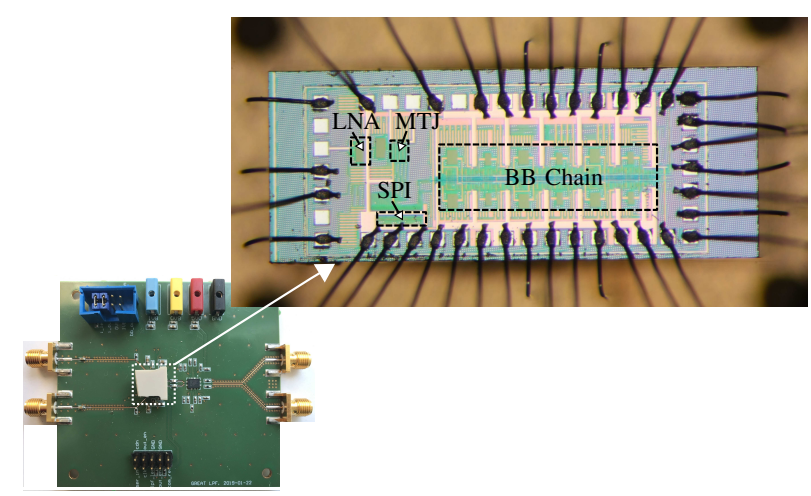

Fig. 6. Chip photograph of the fabricated frequency detector

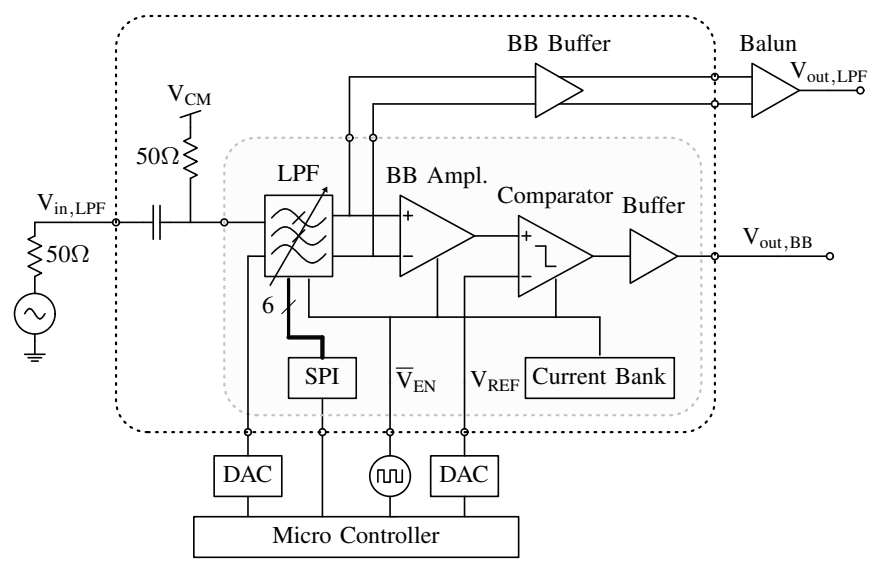

Fig. 7. Schematic of the PCB with the chip under test quency responses corresponding to the filter bit configuration of $b<5: 3>=000$ and $b<2: 0>$ from 000 to 111 . Here we can first see that the cut-off frequency $f_{c, 6 t h}$ is changed accordingly to the corresponding bit configuration. We can also tell that the LPF achieves a transition steepness of $-120 \mathrm{~dB} / \mathrm{dec}$ ade. However, the filter's passband gain $A_{L P, 6 t h}$ decreases when the cut-off frequency $f_{c}$ becomes higher, which is a result of process variations. To compensate the loss of $A_{L P, 6 t h}$, the higher 3 bits of the LPF, $b<5: 3>$, are tuned. Fig. 9 shows the 8 frequency responses after adjustment of the filter's $A_{L P, 6 t h}$. Here we can see that the reduction of the passband gain can be successfully compensated, and the specified filter characteristics are satisfied. In the following tests, we set the filter's bit configuration $b<5: 0>$ to 011011 , which corresponds to a DC current consumption of around $1.34 \mathrm{~mA}$ at $1.8 \mathrm{~V}$.

To characterize the filter's transient behavior, we used a waveform generator Keysight 33600A with two channels, that generate, respectively, a $10 \mathrm{MHz}$ and $20 \mathrm{mV}_{\mathrm{PP}}$ sine wave signal for the LPF's input as well as a $10 \mathrm{KHz}$ low enable signal for the LPF's $\bar{V}_{\mathrm{EN}}$. The settling time is defined as the time slot the LPF takes from the start of its power-up signal until its output signal reaches $90 \%$ of its steady state amplitude. Fig. 10 shows the measured filter's output signal with its

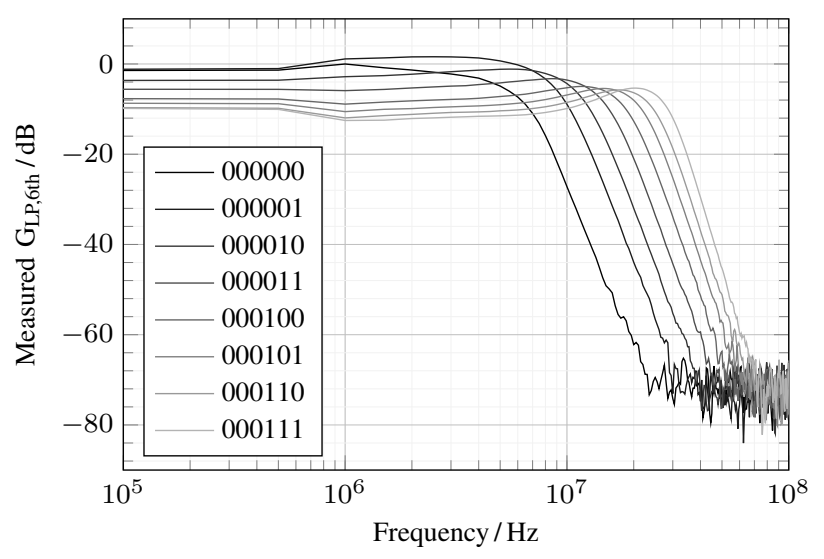

Fig. 8. Measured filter frequency responses without $A_{L P, 6 t h}$ compensation

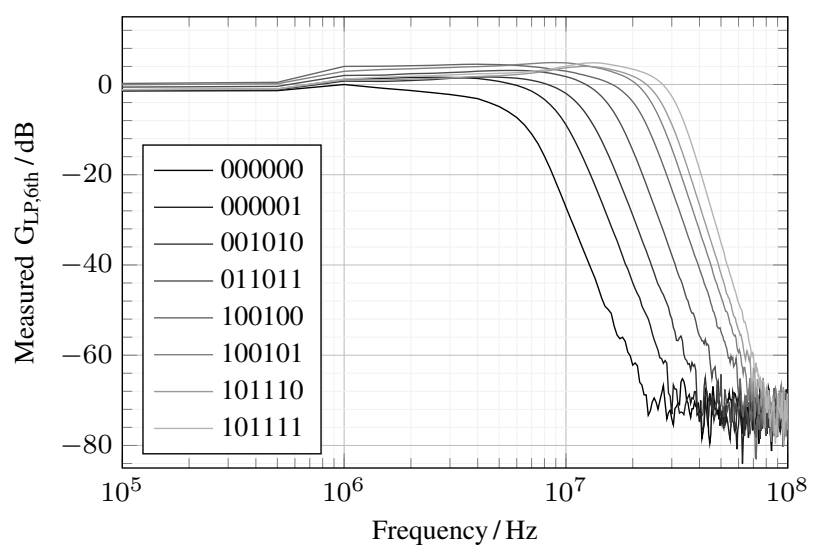

Fig. 9. Measured frequency responses with $A_{L P, 6 t h}$ compensation 


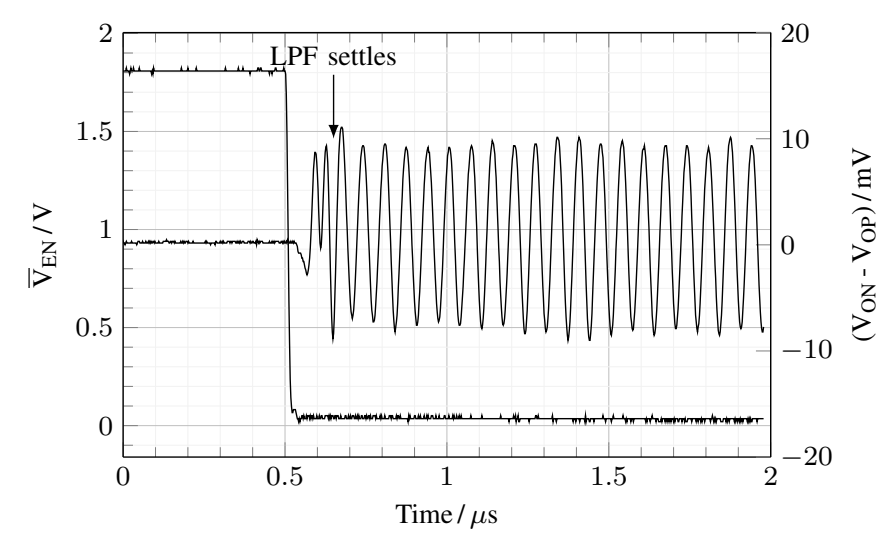

Fig. 10. Measured filter output signal with $\overline{\mathrm{V}}_{\mathrm{EN}}$ being applied

low enable signal $\overline{\mathrm{V}}_{\mathrm{EN}}$. It can be seen that $\overline{\mathrm{V}}_{\mathrm{EN}}$ starts to drop at $0.5 \mu \mathrm{s}$, and the LPF settles at around $0.614 \mu \mathrm{s}$. Thus, the directly observed settling time is $140 \mathrm{~ns}$. This time slot, however, includes the delay time caused by the on-board output buffer, the transmission line on the $\mathrm{PCB}$, the balun and the cables, which according to our characterization is approximated to $30 \mathrm{~ns}$. Thus, the measured settling time is $110 \mathrm{~ns}$ which matches the simulated value of $105 \mathrm{~ns}$ very well.

The performance of the LPF and comparison with prior works are summarized in Table V. Here we can see that the fabricated $6^{\text {th }}$-order LPF achieves the lowest DC power consumption per pole among the state-of-the-art LPFs. Moreover, it demonstrates a fast switchable functionality that the other LPFs do not have. The switch-on time of $110 \mathrm{~ns}$ is very low. Thanks to the low power consumption and fast switchablity, our proposed LPF is an ideal candidate for ultra low power and especially duty-cycled applications, such as, wake-up receivers.

TABLE V

COMPARISON WITH STATE-OF-THE-ART LPFS

\begin{tabular}{c|ccccc}
\hline & This work & {$[13]$} & {$[14]$} & {$[15]$} & {$[16]$} \\
\hline Technology & $\begin{array}{c}180 \mathrm{~nm} \\
\text { CMOS }\end{array}$ & $\begin{array}{c}180 \mathrm{~nm} \\
\text { CMOS }\end{array}$ & $\begin{array}{c}180 \mathrm{~nm} \\
\text { CMOS }\end{array}$ & $\begin{array}{c}90 \mathrm{~nm} \\
\text { CMOS }\end{array}$ & $\begin{array}{c}65 \mathrm{~nm} \\
\text { CMOS }\end{array}$ \\
\hline Topology & $\begin{array}{c}\text { TT } \\
\mathrm{g}_{\mathrm{m}}-\mathrm{C}\end{array}$ & $\begin{array}{c}\text { Active } \\
\text { RC }\end{array}$ & $\begin{array}{c}\text { Sallen } \\
\text { Key }\end{array}$ & $\mathrm{g}_{\mathrm{m}}-\mathrm{C}$ & $\begin{array}{c}\text { Active } \\
\mathrm{RC}\end{array}$ \\
\hline Filter order & 6 & 4 & 4 & 6 & $2 / 4 / 6 / 8$ \\
\hline $\begin{array}{c}\text { Settling } \\
\text { time }(\mathrm{ns})\end{array}$ & $\mathbf{1 1 0}$ & - & - & - & - \\
\hline $\mathrm{V}_{\mathrm{DD}}(\mathrm{V})$ & 1.8 & 1.8 & 1.8 & 1.0 & 1.2 \\
\hline $\begin{array}{c}\mathrm{P}_{\mathrm{DC}} \\
(\mathrm{mW})\end{array}$ & $\mathbf{2 . 4 1}$ & 12.4 & 3.2 & 4.35 & $\begin{array}{c}1.72- \\
9.6\end{array}$ \\
\hline $\begin{array}{c}\mathrm{P}_{\mathrm{DC}} \text { per } \\
\text { pole }(\mathrm{mW})\end{array}$ & $\mathbf{0 . 4}$ & 3.1 & 0.8 & 0.725 & $\begin{array}{c}0.86- \\
1.2\end{array}$ \\
\hline $\mathrm{f}_{\mathrm{c}}(\mathrm{MHz})$ & 10 & 22.5 & 28.8 & $8.1-13.5$ & $0.2-20$ \\
\hline $\begin{array}{c}\text { Passband } \\
\text { gain }(\mathrm{dB})\end{array}$ & $0.5-$ & 0.5 & -3 & $0-$ & 20 \\
\hline Size $\left(\mathrm{mm}^{2}\right)$ & $\mathbf{0 . 3}$ & 0.357 & 0.12 & 0.239 & 0.8 \\
\hline & & & & & \\
\hline
\end{tabular}

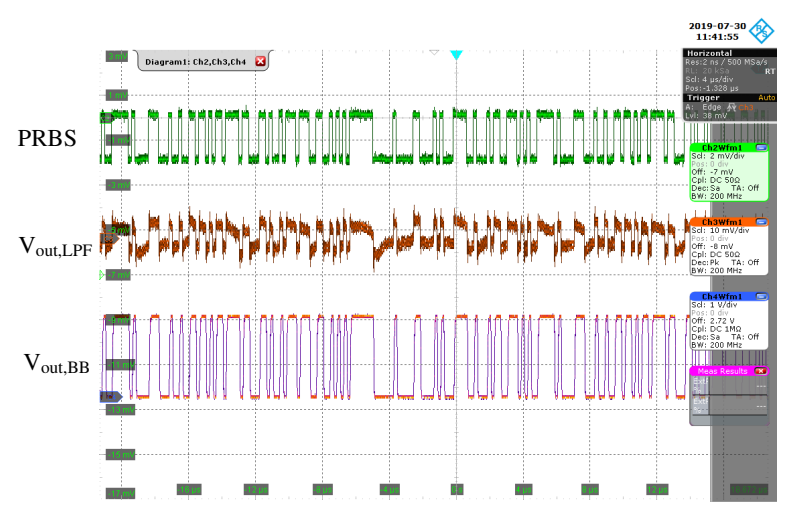

Fig. 11. Time trace of the PRBS, the output of the LPF and comparator.

\section{B. Characterization of the BB Chain}

A bit error rate (BER) test was performed to quantitatively characterize the functionality of the analogue BB chain. In order to model the output of an MTJ device, we used the PRBS function of a waveform generator Keysight 33600A to generate a pseudo-random bit stream (PRBS). The data rate of the PRBS was set to $5 \mathrm{Mbps}$. The reference voltage of the comparator $\mathrm{V}_{\mathrm{REF}}$ was set to $0.7 \mathrm{~V}$ via the micro-controller. An oscilloscope Rohde\&Schwarz RTO 1044 was used to sample the PRBS, the output of the LPF and the comparator. The sampled bit length of the PRBS was set to $10^{6}$. $V_{\mathrm{PP}}$ of the PRBS was swept from $3.5 \mathrm{mV}$ to $1.5 \mathrm{mV}$ with a step of $0.5 \mathrm{mV}$. Fig. 11 shows a $40 \mu$ s time trace of the PRBS, the output of the LPF and comparator, when the PRBS was at a date rate of $5 \mathrm{Mbps}$ with $\mathrm{V}_{\mathrm{PP}}$ equal to $2 \mathrm{mV}$. It can be seen, for the observed time slot, the BB chain has successfully interpreted the input BB signal to the corresponding digital bit flow.

Moreover, a Matlab script was developed to compare the data between the PRBS and the output of the comparator and calculate the BER of each test case. Table VI summarizes the $B E R$ of the $B B$ chain at different $V_{P P}$ of the input $B B$ signal. It can be concluded that if the $\mathrm{BB}$ signal converted by the MTJ has a $V_{P P}$ greater than $2.5 \mathrm{mV}$ or even $2.0 \mathrm{mV}$, the MTJ based RF signal detector can work properly.

TABLE VI

MEASUREd BER OF THE BB CHAIN AT 5 MBPs

\begin{tabular}{c|ccccc}
\hline Vpp & $3.5 \mathrm{mV}$ & $3.0 \mathrm{mV}$ & $2.5 \mathrm{mV}$ & $2.0 \mathrm{mV}$ & $1.5 \mathrm{mV}$ \\
\hline BER & $<10^{-6}$ & $<10^{-6}$ & $<10^{-6}$ & $1.3 \cdot 10^{-5}$ & $2.5 \cdot 10^{-4}$ \\
\hline
\end{tabular}

\section{CONCLUSION}

This work has presented an analogue BB chain for an MTJ based RF signal detector fully integrated in a hybrid CMOSMTJ technology. The BB chain contains a fully-differential $6^{\text {th }}$-order $\mathrm{g}_{\mathrm{m}}-\mathrm{C}$ based LPF, a BB amplifier, a comparator, a current bank and a digital SPI.

The fabricated LPF with a cut-off frequency of $10 \mathrm{MHz}$ achieves a very low DC power consumption of $2.41 \mathrm{~mW}$. Its DC power per pole of $0.4 \mathrm{~mW}$ is the lowest among the stateof-the-art LPFs. Moreover, the LPF can be switched on and 
off very fast within $110 \mathrm{~ns}$. The fast switch-ability, remarkably low power consumption and a competitively small silicon area allow this LPF to improve the state of the art.

In addition, the complete analogue $\mathrm{BB}$ chain is able to transform a $2.5 \mathrm{mV}_{\mathrm{PP}}, 5 \mathrm{Mbps} \mathrm{BB}$ signal into digital data with a BER fewer than $10^{-6}$. The BB chain consumes a DC current of $2.85 \mathrm{~mA}$ from a $1.8 \mathrm{~V}$ supply including all bias circuits. To achieve power efficiency, the $\mathrm{BB}$ chain is able to operate under the duty-cycling mode. The switch-on time of the BB chain is within $200 \mathrm{~ns}$.

\section{ACKNOWLEDGMENT}

The research leading to these results has received funding from (FP7-ICT-2011-8) under grant agreement N.317950 (GREAT). This research is also funded by the European Social Fund (ESF) as well as by the tax revenue on the basis of the budget granted by the deputies of the Saxon State Parliament.

\section{REFERENCES}

[1] P. Villard, U. Ebels, D. Houssameddine, J. Katine, D. Mauri, B. Delaet, P. Vincent, M. Cyrille, B. Viala, J. Michel, J. Prouvee, and F. Badets, "A GHz Spintronic-Based RF Oscillator," IEEE Journal of Solid-State Circuits, vol. 45, no. 1, pp. 214-223, Jan 2010.

[2] A. A. Tulapurkar, Y. Suzuki, A. Fukushima, H. Kubota, H. Maehara, K. Tsunekawa, D. D. Djayaprawira, N. Watanabe, and S. Yuasa, "SpinTorque Diode Effect in Magnetic Tunnel Junctions," Nature, vol. 438, p. 339-342, September 2005.

[3] S. Miwa, S. Ishibashi, H. Tomita, T. Nozaki, E. Tamura, K. Ando, N. Mizuochi, T. Saruya, H. Kubota, K. Yakushiji, T. Taniguchi, H. Imamura, A. Fukushima, S. Yuasa, and Y. Suzuki, "Highly Sensitive Nanoscale Spin-Torque Diode," Nature Materials, vol. 13, p. 50-56, October 2013.

[4] L. Zhang, B. Fang, J. Cai, M. Carpentieri, V. Puliafito, F. Garesci, P. Khalili Miri, G. Finocchio, and Z. Zeng, "Ultrahigh Detection Sensitivity Exceeding $10^{5}$ V/W in Spin-Torque Diode," Applied Physics Letters, vol. 113, September 2018.

[5] U. Ebels, J. Hem, A. Purbawati, A. R. Calafora, C. Murapaka, L. Vila, K. J. Merazzo, E. Jimenez, M. . Cyrille, R. Ferreira, M. Kreissig, R. Ma, F. Ellinger, R. Lebrun, S. Wittrock, V. Cros, and P. Bortolotti, "Spintronic Based RF Components," in 2017 Joint Conference of the European Frequency and Time Forum and IEEE International Frequency Control Symposium (EFTF/IFCS), July 2017, pp. 66-67.

[6] R. Ma, A. Purbawati, M. Kreißig, F. Protze, A. Ruiz-Calaforra, J. Hem, U. Ebels, and F. Ellinger, "Spin Torque Oscillator Based BFSK Modulation," in 2017 13th Conference on Ph.D. Research in Microelectronics and Electronics (PRIME), June 2017, pp. 1-4.

[7] M. Kreißig, S. Wittrock, F. Protze, R. Lebrun, K. J. Merazzo, M. Cyrille, R. Ferreira, P. Bortolotti, U. Ebels, V. Cros, and F. Ellinger, "Hybrid PLL System for Spin Torque Oscillators Utilizing Custom ICs in 0.18 $\mu \mathrm{m}$ BiCMOS," in 2017 IEEE 60th International Midwest Symposium on Circuits and Systems (MWSCAS), Aug 2017, pp. 910-913.

[8] H. S. Lee, S. H. Kim, T. H. Jang, H. Park, B. Min, S. Park, C. S. Park, "Power-Efficient Spin-Torque Nano-Oscillator-Based Wireless Communication With CMOS High-Gain Low-Noise Transmitter and Receiver," in IEEE Transactions on Magnetics, vol. 55, no. 5, pp. 1-10, May 2019.

[9] S. Jenkins, R. Lebrun, E. Grimaldi, S. Tsunegi, and P. Bortolotti, "Spin-Torque Resonant Expulsion of the Vortex Core for an Efficient Radiofrequency Detection Scheme," in Nature Nanotechnology, Nature Publishing Group, 11(4) 2016, pp. 360-364.

[10] M. Tahoori, S. M. Nair, R. Bishnoi, S. Senni, J. Mohdad, F. Mailly, L. Torres, P. Benoit, P. Nouet, R. Ma, M. Kreißig, F. Ellinger, K. Jabeur, P. Vanhauwaert, G. D. Pendina, and G. Prenat, "GREAT: Heterogeneous Integrated Magnetic Technology Using Multifunctional Standardized Stack," in 2017 IEEE Computer Society Annual Symposium on VLSI (ISVLSI), July 2017, pp. 344-349.

[11] Y. Sun, Design of High Frequency Integrated Analogue Filters. UK: IET, 2002.
[12] R. Ma, Z. Tibenszky, M. Kreißig, F. Ellinger, "A $0.41 \mathrm{~mW}$ BandTunable 6th-Order IF Filter with 40ns Settling Time in 45nm CMOS RFSOI," 2019 14th European Microwave Integrated Circuits Conference (EuMIC), Sept 2019, pp. 212-215.

[13] A. Pipino, M. D. Matteis, A. Pezzotta, F. Resta, S. D'Amico, and A. Baschirotto, "A 22.5MHz 21.5dBm-IIP3 4th-Order FLFB Analog Filter," in ESSCIRC Conference 2016: 42nd European Solid-State Circuits Conference, Sept 2016, pp. 289-292.

[14] M. D. Matteis, F. Resta, A. Pipino, S. D'Amico, and A. Baschirotto, "A 28.8-Mhz 23-dBm-IIP3 3.2-mW Sallen-Key Fourth-Order Filter with Out-of-Band Zeros Cancellation," IEEE Transactions on Circuits and Systems II: Express Briefs, vol. 63, no. 12, pp. 1116-1120, Dec 2016.

[15] M. S. S. Oskooei, N. Masoumi, M. Kamarei, and H. Sjoland, "A CMOS 4.35-mW +22-dBm IIP3 Continuously Tunable Channel Select Filter for WLAN/WiMAX Receivers," IEEE Journal of Solid-State Circuits, vol. 46, no. 6, pp. 1382-1391, June 2011

[16] Y. Wang, L. Ye, H. Liao, R. Huang, and Y. Wang, "Highly Reconfigurable Analog Baseband for Multistandard Wireless Receivers in 65-nm CMOS," IEEE Transactions on Circuits and Systems II: Express Briefs, vol. 62, no. 3, pp. 296-300, March 2015. 